\title{
La dignidad humana en las investigaciones biomédicas ${ }^{1}$
}

NARCISO MARTINEZ MORAN

Profesor titular de Filosofía del Derecho, UNED

1. PLANTEAMIENTO DE LA CUESTIÓN: NECESIDAD DE

LA BIOÉTICA Y EL BIODERECHO ANTE EL PROGRESO

DE LA BIOMEDICINA Y LA BIOTECNOLOGÍA.

A nadie se le oculta que, en las últimas décadas del siglo $\mathrm{XX}$, la humanidad ha experimentado un avance vertiginoso en el desarrollo de las ciencias biomédicas. $Y$, sin duda, la principal aspiración y la única justificación de todas las investigaciones biomédicas se encuentra en la preocupación y la necesidad que tiene el hombre de afrontar y curar las graves enfermedades que acosas a todos los seres humanos. Por fin el “homo sapiens» de nuestro tiempo es autoconsciente, se ha creído, en serio, que realmente está a su alcance el conocimiento profundo de lo que es el ser humano, el descubrimiento de su constitución molecular y de su genoma. Podemos afirmar que la verdadera importancia de las investigaciones biomédicas de los últimos años radica en "identificar los genes y las proteínas implicadas en los procesos patológicos para, a continuación, diseñar estrategias que controlen la expresión de estos genes, 
corregir sus mutaciones o sintetizar fármacos que, específicamente, se unan a estas proteínas"2. Esta preocupación científica, gestada ya en las últimas décadas del siglo XX y desarrollada de manera galopante durante los últimos años, ha comenzado a producir sus mejores frutos en los albores del tercer milenio. Entre los principales retos de la medicina del este siglo XXI que acabamos de estrenar se encuentran la prevención, diagnóstico y tratamiento de las principales enfermedades. Sin duda contribuirán a ello el conocimiento del agenoma humano ${ }^{3}$ y todas las aplicaciones biotecnológicas que tal descubrimiento lleva consigo. Se trata de un hallazgo trascendental para la historia de la medicina por lo que supone de avance en las ciencias sobre la vida humana. A partir de ahora dispondremos de una mayor y mejor información sobre los factores genéticos implicados en muchas de las enfermedades que más preocupan a los seres humanos de nuestro tiempo: alzheimer, diabetes, enfermedades psiquiátricas como la anorexia, la bulimia, la depresión, la ansiedad y la esquizofrenia, etc. etc. . "El enorme cúmulo de información que se generará durante los próximos años -afirma XAVIER ESTIVILL- precisará de cambios sustanciales en la formación de los profesionales de la salud en el ámbito de la medicina genómica"4.

Es obvio que todos los descubrimientos realizados en el ámbito de la medicina y los avances experimentados en el campo de la biotecnología han generado grandes expectativas para toda la humanidad cuyos resultados y beneficios ya han comenzado a evidenciarse en algunos campos concretos de la medicina. Por ejemplo, el progreso en las técnicas de fertilización humana asistida (inseminación artificial, generación ain vitro", congelación y utilización de óvulos fecundados, elección y selección de sexo... etc. $)^{5}$ ha llevado a muchas familias la esperanza y la posibilidad de tener hijos imposibles de engendrar por la vía directa de la unión conyugal.

Con el descubrimiento del genoma humano se abre el camino a múltiples terapias curativas y predictivas (diagnosis prenatal, el cribado genético, etc.) que pueden eliminar o disminuir los efectos de muchas enfermedades ${ }^{6}$. 
La ingeniería genética (a través de la manipulación genética y la investigación con células madre y con células embrionarias) impulsa y posibilita la generación de tejidos y órganos que revolucionarán, sin duda, toda la tecnología de los trasplantes en seres humanos. En los próximos años la biotecnología se desarrollará, sin duda, hasta cotas insospechadas ${ }^{7}$.

Los avances farmacológicos, aunque en ocasiones plantea serios problemas su utilización y suministro ${ }^{8}$, y las nuevas técnicas de reanimación y tratamiento del dolor permitirán una vida más digna al enfermo terminal, posibilitando incluso un cambio en las actitudes y los planteamientos frente a la eutanasia?.

En efecto, estos y otros muchos ejemplos que podríamos aducir constituyen una demostración patente de que, durante las últimas décadas del siglo $\mathrm{XX}$, las ciencias biomédicas han experimentado un avance vertiginoso con descubrimientos de vital trascendencia para los seres humanos, que han revolucionado todas las concepciones éticas y jurídicas acerca de las condiciones en que deben desarrollarse las investigaciones llevadas a cabo en las ciencias sobre la vida humana, porque, junto a los grandes beneficios que todos los progresos y descubrimientos suponen para la humanidad, se ha incrementado también la incertidumbre sobre los problemas potenciales que afectan a la propia especie humana.. Por esta razón, en el panorama de las ciencias sobre la vida del hombre se ha desarrollado al mismo tiempo -y destaca hoy con fuerza- el estudio de la "Bioética". Como nueva rama del saber ético proporciona un ámbito teórico especial para abordar problemas antiguos y nuevos relacionados con la vida humana. Su ámbito de estudio o contenido nos viene suministrado por los datos de las ciencias de la vida, como la Biología, la Medicina, la Genética, la Antropología, la Sociología... y todos los experimentos y actuaciones que plantea el cuidado de la salud y la vida individual y social del ser humano, contemplados desde la perspectiva de la moralidad en ellos imbricada. Pero lo que la ha elevado al primer plano de la actualidad han sido los rápidos avances de las ciencias Biológicas y Médicas. 
Nadie duda hoy que algunas investigaciones biomédicas se sitúan en la frontera de la Ética y del Derecho generando un cierto grado de oposición cuando no rechazo. En efecto, al manipular directamente sobre seres humanos pueden ocasionarse agresiones genéticas que lleven incluso la destrucción de la vida humana (aborto eugenésico, eutanasia..), a distorsionar el propio modo del ser humano (clonación) o a otros atentados contra la dignidad de la persona (esterilización, contracepción, eliminación de embriones congelados etc.).

Todos los citados, y muchos otros, han sido problemas de debate en el final del siglo XX y siguen siéndolo en el inicio de este nuevo siglo. En los últimos años estamos probablemente asistiendo a la revolución más trascendental para la historia del hombre y de la humanidad. No es exagerado afirmar que nos encontramos ante una auténtica revolución de la Biología y de la Medicina que lanzan un reto decisivo a la humanidad y ante la cual la Ética y el propio Derecho no pueden permanecer impasibles, no pueden quedarse callados, pues no se trata de problemas pacíficos que se resuelvan fácilmente en el ámbito sosegado de la ciencia. Por ello el juicio de la Ética ha sido y sigue siendo imprescindible en cuestiones de tanta trascendencia para todos los seres humanos. La Ética y el Derecho tienen que intervenir necesariamente para iluminar el camino a los científicos.

Por ello una vez más debemos plantear el interrogante ¿́Todo lo que puede hacerse técnicamente se debe hacer desde el punto de vista ético y jurídico?. Se trata, sin duda, del eterno interrogante sobre la relación entre técnica y ética, entre ciencia y conciencia o si se quiere entre ciencia, ética y derecho.

Los progresos en el campo de la Medicina y en las ciencias de la vida, así como las posibilidades de actuación de la Biotecnología, colocan al hombre ante situaciones nuevas, impensables hace tan sólo algunos años y nos obligan a dar respuestas diferentes a una nueva concepción de los valores humanos tradicionales. En efecto los científicos a veces se encuentran desconcertados y buscan en filósofos y juristas una respues- 
ta a los interrogantes que la ciencia plantea a la Ética y al Derecho. Pero al mismo tiempo debemos señalar también que la Ética y el Derecho tienen muchos interrogantes que plantear a las técnicas y al uso de los resultados de las investigaciones científicas. Por esta razón, en todos los ámbitos de la sociedad, se ha generado un debate que afecta no sólo al campo de la Biología y la Medicina, sino también al de la Ética y el Derecho dando lugar a los estudios de Bioética y Bioderecho ${ }^{10}$.

¿Hasta dónde debe permitirse la manipulación sobre el ser humano? ¿Qué papel desempeña la dignidad humana en el debate sobre las nuevas tecnologías de las ciencias biomédicas? ¿Pueden establecerse límites a las investigaciones médicas? La respuesta a este último interrogante es casi unánime: La investigación científica tiene como único límite la dignidad humana y el respeto a los Derechos Humanos. Por ello nos veremos obligados a plantear el concepto mismo de dignidad humana, tanto desde el punto de vista genérico como en las situaciones individuales de la casuística en cada realidad concreta.

Los frutos de las investigaciones médicas en las últimas décadas del siglo XX están a la vista. Pero quizá no se vean con tanta claridad las deficiencias que mueven a muchos al rechazo de determinadas investigaciones por entender que las técnicas aplicadas o los resultados conseguidos suponen un atentado contra la propia dignidad humana.

En consecuencia debemos afirmar que es indudable la necesidad de la investigación para el avance y el progreso de las ciencias. Más importante y necesaria aún se presenta la investigación para el progreso de la Medicina, pues no cabe duda que la eficacia curativa y la posibilidad de diagnósticos, incluso predictivos, de muchas enfermedades de la actualidad se deben precisamente a la tenacidad y rigor científico de la investigación Biomédica que ha conseguido logros insospechados. Tan importante es este tipo de investigación que podríamos llegar a considerar la investigación médica como un deber ético. Es un deber de solidaridad de todos aquellos que puedan hacerlo (cada uno en su ámbito) el contribuir al mejoramiento de la calidad de vida de todos los seres humanos. 
Pero al mismo tiempo que la investigación es, a la vez, un derecho y un deber ético se produce la paradoja de que puede resultar un atentado a la Ética. Es precisamente por ello por lo que surge el conflicto entre el derecho y la libertad para investigar y los medios y fines utilizados para llevar a cabo la investigación correspondiente.

En efecto, como en cualquier otro ámbito de la actividad humana, la actividad científica e investigadora no está exenta de condicionamientos éticos o legales. Esto se observa de manera especial en las ciencias médicas dada la trascendencia y dignidad del objeto (el ser humano mismo) sobre el que se investiga. Baste recordar que esta preocupación ética existe desde la antigüedad, pues ya con Hipócrates se formuló el primer código ético conocido. Pero antes de plantearnos cuáles son los límites que deben establecerse para las investigaciones biomédicas debemos conocer el ámbito concreto de actividad al que denominamos ciencia, tecnología e investigación en este ámbito y cuáles son sus auténticas implicaciones.

Aunque la búsqueda del saber no es ajena a las sociedades primitivas y está presente a lo largo de toda la historia de la Humanidad, hemos de reconocer que es a causa de la revolución tecnológica, a finales del siglo XX, cuando el hombre, por primera vez, se siente cuasi creador de la naturaleza. Pero la revolución tecnológica afecta de manera especial a las ciencias de la vida, y más en concreto a la Biología y la Medicina, cuyas técnicas e investigaciones, por su propio objeto (actúan directamente sobre la vida humana) no pueden llevarse a cabo de manera descontrolada sin estar sometidas a ningún tipo de limitación.

Es cierto que el progreso técnico, en Biología y Medicina favorece el progreso y bienestar de la humanidad: se descubren enfermedades y tratamientos farmacológicos o técnicas específicas para su curación. Pero no es menos cierto que se producen riesgos de carácter ético. Por ello la investigación médica, que siempre ha sido reconocida como lícita y necesaria, ha sufrido vetos por diferentes motivos en ocasiones religiosos y, a veces, de carácter puramente ético. Estas limitaciones se han generado 
fundamentalmente en el campo de la investigación clínica. A lo largo de la historia tenemos noticias de multitud de experimentos terapéuticos realizados en grupos de pacientes vulnerables: africanos, pobres, niños, ancianos, dementes..., prisioneros, Estas investigaciones son un claro atentado a la dignidad humana pues es radicalmente inmoral investigar con seres humanos utilizándolos como medios, o, al menos, exclusivamente como medios y no como fines, según la concepción de KANT. Más aún puede ser inmoral experimentar sobre el hombre cuando pueda resultar peligroso para él aunque el resultado sea útil para otros.

Han sido numerosos los atentados que, en nombre de la ciencia, se han realizado contra la dignidad humana. Ha sido de manera especial en la primera mitad del siglo XX cuando la historia de la experimentación sobre los seres humanos ha tomado en ocasiones caminos contrarios a la dignidad humana, en muchas ocasiones bajo un desordenado afán de contribuir al progreso de la ciencia o de alcanzar un protagonismo irresponsable, en otras.

Recordemos los experimentos en la Alemania del Tercer Reich, que constituyeron un claro ejemplo de estos abusos Los médicos nazis que participaron activamente en los asesinatos o tomaron parte en los experimentos con los deportados clamaron por la legitimación moral de sus actos en nombre del progreso científico. Ellos pretendieron contribuir al progreso científico mediante prácticas clínicas y de investigación al servicio de una causa indigna: depurar la raza. Sin embargo lo único que consiguieron fue la degradación del ser humano y de la propia investigación científico-médica. Y uno de los crímenes más odiosos cometidos consistió precisamente en la utilización de los deportados como cobayas para experiencias pseudomédicas. En la mayoría de los campos de concentración existían bloques de "cobayas" -así se les llamaba- especialmente preparados para estas indignas y degradantes experiencias.

Pero estos ejemplos no han sido los únicos hechos lamentables del siglo XX. Recordemos los experimentos del estudio Tuskegee en Alabama en 1932. En 1972 salió a la luz y se supo que, durante cuarenta años, se 
había estado investigando en Estados Unidos el desarrollo de la sífilis sobre un grupo de más de 400 negros pobres que padecían esta enfermedad contagiosa y, habiéndoseles diagnosticado la enfermedad, fueron mantenidos sin tratamiento para estudiar la evolución de la misma en el hombre. Dejarlos sufrir y morir en nombre de la ciencia constituye, cuando menos, un trato vejatorio e indigno para aquellos pacientes y una inmoralidad fragrante para quien realiza tales prácticas. ¿Qué ciencia puede justificar el sufrimiento y la muerte de seres humanos ante la mirada impasible de los investigadores?.

En algún caso para probar determinadas vacunas se inoculó el virus en niños con retraso mental, obteniendo el permiso de los padres, a los que se les engañó diciendo que los niños contraerían la enfermedad en cualquier caso y este experimento les ayudaría a su curación.

Recientemente la insólita y extravagante secta de los Raelianos, que asegura que la Tierra fue creada en un laboratorio por extraterrestres, saltándose todos los controles éticos y jurídicos, ha anunciado que, a través de la empresa Clonaid, está clonando seres humanos «como vía para alcanzar la eternidad». El Dr. Italiano Severino Antiniori, apodado en algunos medios franceses como el «ginecólogo-kamikaze» ha anunciado igualmente que se encuentra trabajando y está a punto de conseguir la clonación de seres humanos, fuera de cualquier control ético o deontológico, a pesar del aluvión de críticas recibidas por toda la comunidad científica internacional.

Estos y otros muchos son claros ejemplos de cómo en países democráticos se vulneran los derechos de las personas en nombre de la ciencia y ponen de relieve los peligros de la investigación sin restricciones. De ahí la necesidad de establecer y legislar determinados límites o condiciones dentro de las cuales debe realizarse toda investigación, para no incurrir permanentemente en los riesgos que estamos denunciando. Los investigadores serios así lo demandan y miran a juristas y filósofos buscando una respuesta a sus interrogantes éticos y jurídicos para no cargar sobre sus conciencias la responsabilidad de la toma de decisiones. 
Si queremos arriesgarnos a aventurar algún tipo de límite veremos que el límite fundamental es el respeto a la dignidad humana y tal vez la finalidad perseguida con la propia investigación que ha de servir, en todo caso, para el beneficio y mejora de la calidad de vida en todos sus ámbitos. La investigación nunca será justificable si única o prioritariamente sirve para la destrucción del ser humano. Recordemos aquí el gran debate internacional planteado en la actualidad sobre las armas de destrucción masiva (químicas y bacteriológicas) que constituyen un grave peligro para toda la humanidad. Sobre las conciencias de muchos investigadores aún resuenan las palabras del creador de la bomba atómica, J. Robert OPPENHEIMER: Antes del lanzamiento de la bomba atómica había dicho que cuando uno ve algo que técnicamente es hermoso sigue adelante hasta conseguirlo. Después de lanzar la bomba atómica declaró ante el Institute of Technology de Massachusetts: "De una manera brutal, que no puede ser desconocida, los físicos hemos conocido el pecado y este es un conocimiento que no se puede desconocer". En la actualidad existen investigadores en el ámbito de la Biología o la Medicina de los que cabría decir que sus actividades son intrínsecamente «pecaminosas», es decir carentes de toda ética, lo que nos obliga a replantearnos el propio concepto de la ética científica. Esto significa que en la época de la técnica y de la Bioética se está operando un cambio cualitativo que tendrá repercusiones evidentes sobre nuestra futura historia.

Estas son las razones de que, para no repetir los errores y aberraciones históricas debamos plantearnos si todo lo que es posible hacer técnicamente está permitido éticamente. El problema por tanto es establecer qué es lo que está permitido y lo que, si llega el caso, deba prohibirse o regular las condiciones de su ejercicio. Esta decisión nos obliga a tomar partido a sabiendas de que nuestra decisión tendrá repercusiones trascendentales en las generaciones futuras. Sin duda la existencia de la legislación actual sobre ensayos clínicos en la Comunidad Europea, que regula y hace especial hincapié en los aspectos éticos, si es interpretada e implementada, permitirá estimular y agilizar una investigación clínica correcta. 
No faltan sin embargo opiniones contrarias que afirman que el intento de controlar la ciencia como tal es pernicioso e inútil y que las acciones deben encaminarse al control de los hombres de ciencia y de las aplicaciones de la misma.

En cualquier caso nos encontramos, como puede verse, ante un tema para el debate, pues la actividad investigadora, como cualquier otra actividad humana, tiene un gran potencial para promover y conseguir inmensos beneficios para el ser humano, pero también puede acarrear enormes males: por un lado la indiscutible capacidad para mejorar la vida del hombre, por otro su capacidad manipuladora, al servicio de los poderes que financian las líneas de investigación y que controlan por lo tanto la ciencia y sus aplicaciones. Es un atentado grave contra la dignidad del ser humanos como individuo y como colectivo, un atentado contra la humanidad, el que la evolución del ser humano esté al servicio de la economía, de las ambiciones de los diferentes poderes, del enriquecimiento de empresas poderosas con capacidad para pagar las investigaciones. Aún más grave resulta el que haya investigadores que se presten a ello.

En consecuencia, en nombre de la dignidad y de los Derechos $\mathrm{Hu}-$ manos, desde la Ética y el Derecho, deben exigirse determinadas condiciones y establecerse los límites precisos para impedir intenciones torcidas y fines bastardos. Las nuevas tecnologías, en ningún caso, pueden volverse contra el hombre sino que deben aportar beneficios y servir a mejorar la calidad de la vida humana. No es posible olvidar que las consecuencias de la actividad científica y tecnológica, hoy más que nunca, afectan a la sociedad en su conjunto, a la humanidad entera.

De ahí que toda la humanidad deba estar representada para tomar decisiones, sin que sea lícito dejar en las exclusivas manos de los científicos, de los grupos de intereses o las naciones más industrializadas las discusiones y las decisiones sobre estos problemas.

Ahora bien, sin perder de vista lo anteriormente expuesto, también hay que hacer un llamamiento a la prudencia. Debemos evitar tanto el 
entusiasmo irracional como el pánico. Si bien es cierto que deben regularse las prácticas científicas, para no caer en irresponsabilidades y en daños irreparables para la humanidad, no es menos cierto que los beneficios que de ellas vamos a obtener supondrán una auténtica revolución de nuestra propia existencia, obligándonos a repensar múltiples aspectos de la misma, sin que ello nos permita caer en una especie de deificación de la ciencia como si de un poder absoluto se tratara, actitud muy extendida, por cierto, en nuestros días, pues -como ha afirmado el Dr. Gómez Sancho- "todos estos avances han generado en la sociedad una especie de delirio de inmortalidad, otorgando al médico una sabiduría, omnipotencia y omnisapiencia que, lógicamente, no posee"

Pues bien, en las páginas que siguen intentaremos reflexionar sobre las implicaciones y repercusiones sobre el impacto, tanto positivo como negativo, de las investigaciones médicas sobre la dignidad humana, pues como ya hemos dicho anteriormente, la dignidad humana se presenta, tal vez, como el único limite a las investigaciones médicas y a la biotecnología. La pregunta a la que que debemos responder es la siguiente. ¿Puede éticamente hacerse todo lo que técnicamente es posible? Quizá al final de las páginas que siguen el lector encuentre una respuesta, o, al menos, luz para afrontar su propia respuesta. Veamos.

\section{2- PERSONA Y DIGNIDAD HUMANA.}

\subsection{LA DIGNIDAD HUMANA: PROBLEMAS CONCEPTUALES.}

Como acabamos de ver es un hecho fácilmente constatable que, durante las últimas décadas del siglo XX las Ciencias Médicas han experimentado un avance vertiginoso. Pero no es menos cierto que cualquier hecho médico, tanto en el ámbito de la ciencia e investigación como en el de la praxis clínica diaria tiene inevitablemente un punto de referencia: el ser humano, o, si se prefiere, la persona humana. En efecto, para comprender el alcance de las ciencias modernas y de las más recientes 
investigaciones que afectan a la vida humana, uno de los conceptos clave que ha de ser tenido en cuenta es el concepto de persona, concepto que, en el ámbito de los Derechos Humanos y, en particular, en el campo de la Bioética y el Bioderecho, es inseparable del concepto de DIGNIDAD HUMANA. Delimitar el concepto de persona no es tarea fácil dado el amplio desacuerdo que sobre el mismo existe en el debate filosófico. Por esta razón no vamos a reproducir aquí la polémica y daremos por supuesto el concepto. En todo caso, para quien desee profundizar en el mismo sugerimos algunas lecturas útiles ${ }^{12}$. Partiendo de la conocida definición que -ya en el siglo VI- hizo BoEcio para quien «persona» es «rationalis naturae individua substancia ${ }^{13}$ (substancia individual de naturaleza racional podría entenderse por persona cualquier individuo (hombre o mujer) de la especie humana, que posee una serie de valores o atributos que constituyen al ser humano como un individuo dotado de una especial dignidad, es decir, de una especial grandeza y nobleza que hacen de él un ser honorable y respetable en sí y por sí mismo. Por esto persona hace referencia a la dignidad del hombre.

Hoy la violación de los derechos humanos en todos los ámbitos es un hecho fácilmente constatable y, en el campo de las nuevas investigaciones y tecnologías biomédicas, se corre el riesgo de atentados contra la dignidad humana que constituye el fundamento mismo de todos los derechos humanos. Es absolutamente imprescindible, por tanto, clarificar el concepto de dignidad humana, para determinar lo que es éticamente posible en el campo de las investigaciones científicas en general y especialmente en aquellas investigaciones cuyo objeto directo son los seres humanos.

En la actualidad la dignidad humana es una realidad reconocida universalmente. De ella se habla en la calle, se escribe en la prensa y en los libros, se debate en los parlamentos y se juzga en los tribunales. La dignidad humana está reconocida en todas las Declaraciones contemporáneas de Derechos. Pero es realmente difícil elaborar un concepto de «dignidad humana` dado que existen diferentes concepciones de la mis- 
ma que hacen imposible el acuerdo o consenso, tanto sobre su contenido como sobre la extensión de los sujetos a quienes debe atribuirse la llamada «dignidad humana*. Se dice que toda persona tiene una dignidad propia e irrenunciable. Todas las cosas tienen una cierta dignidad pero la dignidad de la persona y la de las cosas no tienen el mismo valor, no son magnitudes ontológicamente correlativas.

¿Qué es la dignidad?. ¿Por que decimos que el hombre posee dignidad y qué queremos significar cuando realizamos tal afirmación? ¿Qué sentido tiene hablar de dignidad humana?

La palabra dignidad significa excelencia (eminencia, importancia, sublimidad), grandeza (grandiosidad, realce, importancia), decoro (honor, nobleza, respetabilidad, gloria, esplendor), gravedad (importancia, trascendencia); significa ser distinguido, egregio, eminente, eximio, ilustre, famoso, insigne, notable, preclaro, prestigioso, renombrado, reputado etc. etc.. El diccionario de la Lengua Española define la dignidad como "gravedad y decoro de las personas en la manera de comportarse" ${ }^{14}$. De aquí que la dignidad se predique también de los cargos honoríficos o de la autoridad de las personas. Téngase en cuenta que, entendida así la dignidad humana, se refiere a la perspectiva ética de la misma, dado que se relaciona con la acción personal y con los comportamientos prácticos, o se asimila al rol social que cada uno desempeña. Es obvio que en este ámbito unas personas sean más dignas que otras en función de la grandeza o el prestigio, de la bondad o eticidad de sus actos, o del rol social que desempeñan. Y desde el punto de vista ético cada individuo se hace acreedor de un grado determinado de dignidad o indignidad en función de sus actos.

Este es el sentido que le atribuye Santo Tomás cuando escribe: "en las comedias y tragedias griegas se representaba a personajes famosos y se impuso el nombre de persona para indicar a alguien con dignidad. Por eso en las iglesias empezó la costumbre de llamar personas a los que tienen alguna dignidad, por lo que algunos definen la persona diciendo que es la hipóstasis distinguida por la propiedad relativa a la digni- 
dad"15. Pero Santo Tomás no se queda en este significado de la dignidad. En otro lugar afirma que "la persona es lo más perfecto que existe en toda la naturaleza, es decir lo que subsiste en la naturaleza racional"l6 por lo que el término persona se utiliza para designar precisamente aquellos seres que poseen una dignidad intrínseca, es decir ontológica, propia de todos los seres humanos por igual. En efecto, debe aclararse que, cuando afirmamos que el hombre en cuanto persona es un ser que posee dignidad, nos referimos a todo ser humano vivo en cuanto que su existencia como tal no depende del ejercicio «actual» de la razón o de la autoconciencia en ejercicio permanente. Estamos hablando de la persona en sentido ontológico y no desde la perspectiva simplemente fenomenológica ${ }^{17}$.

En efecto, desde la perspectiva ética o fenomenológica, tal como acabamos de ver cabe afirmar que unas personas son más dignas que otras. Pero ipodemos afirmar que unas personas son más dignas ónticamente que otras? Rotundamente no, porque ontológicamente todos los seres humanos son igualmente dignos. Veamos: En el origen etimológico se aplicó el concepto de persona al hombre por considerar que todo hombre es ser digno. No es que el hombre sea digno por el hecho de ser persona sino, a la inversa, se aplicó este término a todo hombre en cuanto que el término persona expresaba una entidad (el ser humano) dotada de dignidad, o mejor, constituida por la dignidad porque era, en el mundo de la naturaleza, la dignidad misma. Así lo había entendido también San Buenaventura para quien "la persona es la expresión de la dignidad y la nobleza de la naturaleza racional. Y tal nobleza no es una cosa accidental que le fuera sobreañadida a esta naturaleza, sino que pertenece a su esencia"18. Este es el sentido que le da San Agustín a sus palabras cuando afirma que "Dios, sabio creador y justo ordenador de todas las naturalezas, concedió al hombre la máxima dignidad entre los seres de la tierra"19, o cuando escribe que "nada hay más poderoso que esta criatura que se llama la mente racional, nada más sublime que ella; lo que está sobre ella ya es el Creador"20. Ciertamente hablar de la digni- 
dad de la persona es expresar su rango o categoría. "Ser persona es un rango, una categoría que no tienen los seres irracionales. Esta prestancia o superioridad del ser humano sobre los que carecen de razón es lo que se llama la dignidad de la persona humana"21.

Debe quedar claro que la dignidad de la persona supone una superioridad de ésta sobre los seres que carecen de razón o de personalidad pero no admite discriminación alguna con otros seres humanos por razón de nacimiento, sexo, raza, opinión, creencia o cultura., sino que todos los hombres son iguales en dignidad. En palabras del Papa León XIII "la igualdad de los hombres consiste en que, teniendo todos la misma naturaleza, están llamados todos a la misma eminente dignidad de los hijos de Dios"22.

\subsection{DIGNIDAD MORAL Y DIGNEIDAD ${ }^{23}$.}

Para comprender mejor el significado de la dignidad humana y conceptuarla adecuadamente, los filósofos han distinguido entre dignidad moral y dignidad ontológica o digneidad. Santo Tomás por ejemplo llegó a justificar el que se matase como a una bestia al hombre pecador por entender que toda persona que se degrada éticamente se convierte en un ser indigno, no sólo moralmente sino también ónticamente, convirtiéndose en «una bestia». Ciertamente esta afirmación parece una contradicción en la propia filosofía tomista en la que se resalta precisamente la dignidad óntica de la persona.. Por ello entendemos que debe superarse esta distinción entre la dignidad moral y la dignidad óntica, tal como es entendida por Santo Tomás (evidentemente más desde un punto de vista teológico que filosófico, pues él se refiere al pecado, es decir la degradación del hombre que se atreve a desafiar a Dios). Superando este planteamiento sostenemos que la persona puede degradarse en su dignidad moral en tanto actúe inmoralmente pero jamás puede ser tratado como una bestia, pues conserva siempre su dignidad óntica, ya que el inmoral no deja de tener racionalidad y libertad, no deja de ser persona. No por el hecho de hacer un mal uso de su autonomía deja de ser 
autónomo. Es decir, a pesar del mal uso de la libertad el hombre sigue siendo libre y por tanto en posesión de su dignidad ${ }^{24}$.

.Para $\mathrm{KANT}^{25}$ la personalidad se refleja en la autonomía, en la libertad. La dignidad de la persona radica, por tanto, en su actuar libre. El hombre por ser persona puede actuar responsable y libremente. No obstante, la teoría kantiana que sitúa la dignidad humana en la autonomía presenta algunas lagunas e interrogantes. ¿Qué sucede con aquellas personas que aún no han llegado a su madurez, al pleno desarrollo de su autonomía?. ¿Qué dignidad atribuiremos a las personas cuya conducta sea inmoral?. Si para KANT la medida de la dignidad humana viene determinada por el comportamiento moral en libertad, en autonomía, ¿qué pensar entonces del malvado?. ¿Qué puede hacerse con los que algunos califican de infra-hombres (embriones, deficientes, dementes, enfermos, ancianos...)?. ¿Y qué decir de las mujeres y los hombres de piel negra que, según el propio KANr, estaban excluidos del voto porque no habían llegado a la mayoría de edad? ${ }^{26}$.

Como puede observarse, cuando se habla de dignidad del comportamiento moral de la persona, existe un cierto grado de confusión con la dignidad de la persona en sí misma considerada. Por esta razón cabe introducir el neologismo de digneidad para referirnos a la dignidad ontológica, premoral, de la persona, como ser digno por el sólo hecho de ser persona, e incluso al margen de su comportamiento moral. En este sentido la dignidad se da en la praxis de la persona y la digneidad es previa a aquella, la digneidad es el fundamento de la posibilidad de la dignidad. La digneidad de la persona le acompaña siempre por el hecho de ser cualitativamente distinto de los entes que le rodean en el universo de lo creado: por su racionalidad, su relacionalidad, su libertad, su eticidad etc., es decir aquello que la persona y sólo ella posee en el orden de la naturaleza ${ }^{27}$.

La distinción que hemos establecido goza de una especial significación dado que de ella depende el respeto que se tenga a los derechos de todos los seres humanos, especialmente en el ámbito de las investiga- 
ciones y nuevas tecnologías médicas, a las que venimos refiriéndonos. Y, supuesta la trascendencia de tales investigaciones de cara al futuro, su alcance adquiere una importancia y significación aún más relevante, pues está en juego la concepción misma del hombre. Yo diría más, está en juego el destino futuro de la humanidad.

a) La dignidad ética hace referencia no al ser sino al obrar. En este sentido el hombre se hace él mismo digno cuando su conducta está de acuerdo con lo que es considerado moralmente bueno. Esta dignidad es el fruto de una conducta conforme al bien y no es poseída por todos de la misma manera.

Para la tesis, en la que impera el principio de la autonomía o de la autoconciencia y reconoce como principio supremo de la investigación o de la relación médico-paciente el de beneficencia, sin ninguna vinculación con bienes que trasciendan a los sujetos, la ética es considerada como una ética puramente procedimental de solución de conflictos privada de toda significación racional. Y dado que los principios de autonomía y de autoconciencia, e incluso el de beneficencia constituyen los principios de una ética puramente formal, es decir, carente de contenido objetivo, planea sobre ella la duda de qué significa hacer el bien en un contexto en el que se ha renunciado a la capacidad racional humana de reconocer algún valor objetivo además del de no recurrir a la fuerza.

En esta concepción el embrión no posee una dignidad intrínseca sino que vale en la medida en que posea una cierta significación para quienes esperan su venida al mundo; no tiene más derechos que un animal, es decir, solo debe tenerse en cuenta su sensibilidad y evitar el causarle sufrimientos inútiles. Los seres humanos todavía no nacidos no puede decirse que sean dignos por su comportamiento moral, pues, de facto, no tienen aún comportamientos que puedan calificarse como morales al carecer de autoconciencia y de autonomía. De idéntica forma una persona que se encuentre en coma clínico profundo sólo recibe las acciones de otros pero él no realiza acción libre alguna. Algo similar ca- 
be decir de un deficiente psíquico profundo, del loco, del enfermo en estado inconsciente -aunque sea transitoriamente- o en coma, etc.

Todos ellos carecerían de dignidad. Pero su dignidad no viene dada por su acción autónoma en el orden ético pues están imposibilitados para realizar conductas calificables de éticas. Sin embargo todos estos seres son humanos que no por ello dejan de tener su dignidad intrínseca, es decir, ontológica. Todos poseen digneidad ${ }^{28}$.

b) La dignidad ontológica o «digneidad es la dignidad intrínseca inseparablemente unida al propio hombre y es la misma para todos los seres humanos. Desde esta perspectiva todo ser humano es un ser digno y, por tanto, no puede ser sometido a tratamientos degradantes como tortura, malos tratos, manipulaciones de su propio ser. Las personas son dignas «per se», y no sólo son dignas éticamente, porque, para quien no puede realizar conductas libres, sus actos no son ni dignos ni indignos, pero su ser, su personalidad sí contiene dignidad. Como ya hemos dicho se es persona porque se es digno. Es por esta razón por la que se defiende el «no a la pena de muerte», inclusive para los criminales, los malhechores, los terroristas..., por muy indignos, condenables y éticamente reprobables que parezcan sus actos. A pesar de todo se les considera personas con toda su dignidad ontológica. Es por su digneidad -no por la indignidad de sus actos, no por su autoconciencia o por su autonomía- por la que debe respetarse su vida, su integridad y sus derechos personales.

Por la misma razón no podemos fijarnos exclusivamente en la autonomía de los actos para afirmar que las personas no nacidas, los niños, los dementes, los enfermos en estado de coma, los ancianos tienen, o no, dignidad pues igualmente son personas dotadas de digneidad total e igual a todos los seres humanos, lo que hace que deba respetarse su vi$\mathrm{da}$, su integridad física y todos sus derechos inherentes a la persona humana. Es decir que sobre ellos no pueden realizarse investigaciones degradantes que pongan en riesgo su vida o su integridad física y moral, es decir que puedan menoscabar su dignidad como personas. 
En consecuencia, de todo lo expuesto, cabe afirmar que el hombre no es persona por su posibilidad de actuar moralmente de forma autónoma. Al contrario, por ser persona puede obrar responsable y libremente, de donde se deduce que su digneidad es previa a la dignidad de sus comportamientos. Es desde esta perspectiva desde la que tendría sentido la expresión Kantiana: «el hombre es fin en sí mismo», pues los seres humanos no son personas porque sean tratados como " $f$ in en si mismos"; al contrario, los seres humanos deben ser tratados como afin. por ser personas, es decir, por ser dignas en sí, por su digneidad. Todos los seres humanos son respetables por sí mismos ${ }^{29}$.

\subsection{EL RECONOCIMIENTO Y GARANTÍA DE LA DIGNIDAD EN LAS DECLA-} RACIONES Y PACTOS INTERNACIONALES ${ }^{30}$.

En las Declaraciones y Pactos Internacionales de Derechos, tanto en las de carácter general como las más recientemente aprobadas para materias específicas relacionadas con la bioética se reconoce, en todas ellas, la dignidad intrínseca de todo ser humano.

a) Por ejemplo, la Declaración Universal de Derechos Humanos se inicia con las siguientes palabras ¿CONSIDERANDO que la libertad, la justicia y la paz en el mundo tienen por base el reconocimiento de $l a$ dignidad intrínseca y de los derechos iguales e inalienables de todos los miembros de la familia humana ${ }^{31}$... Hemos de destacar la trascendencia que tiene la dignidad humana cuando la propia Declaración Universal de Derechos Humanos se abre con una mención expresa a la dignidad. Pero hay que resaltar sobre todo que la Declaración se refiere expresamente a la «dignidad intrínseca», no a la dignidad moral de los actos, reconociendo que tal dignidad es poseída por todos los seres humanos y que ella constituye el fundamento de los grandes valores o derechos de la humanidad la libertad, la justicia y la paz.. Y más adelante vuelve a resaltar la dignidad humana: "CONSIDERANDO -diceque los pueblos de las Naciones Unidas han reafirmado en la Carta su fe en los derechos fundamentales del hombre, en la dignidad y el va- 
lor de la persona humana y en la igualdad de derechos de hombres y mujeres; .... ${ }^{32}$.

La trascendencia de la dignidad humana se reconoce de nuevo en la Declaración Universal cuando vuelve a comenzar el propio articulado no sólo con la referencia expresa a la dignidad sino también su pertenencia a todos los seres humanos: "Todos los seres humanos nacen libres e iguales en dignidad y derechos ... ${ }^{33}$. En efecto, al referirse a atodos los seres humanos» está expresando la universalidad de los derechos humanos y la universalidad de la dignidad, «sin distinción alguna de raza, color, sexo, idioma, religión, opinión política o de cualquier otra índole, origen nacional o social, posición económica, nacimiento o cualquier otra condición ${ }^{34}$. Evidentemente la expresión «cualquier otra condición quiere significar que no existe absolutamente ningún motivo de discriminación en cuanto a la igual dignidad de todos los seres humanos. Lógicamente tampoco cabe discriminar a los niños, ni a los concebidos -aunque aún no hayan nacido- desde que adquieran la condición de humanos, ni a los ancianos, ni a los disminuidos físicos o psíquicos en tanto sean humanos. Esta precisión adquiere especial relevancia en la actualidad con el avance de las investigaciones y las nuevas tecnologías biomédicas ${ }^{35}$, tanto en el inicio de la vida (estatuto del embrión y reproducción asistida) ${ }^{36}$ como en el final de la misma (cuidados paliativos del enfermo terminal, eutanasia... $)^{37}$, pasando por todas las investigaciones sobre el genoma humano y las investigaciones en la practica médica ( historias clínicas, derecho a la intimidad etc.) ${ }^{38}$.

Todos los Pactos y Convenios de Derechos, tanto internacionales como europeos, que se dirigen a la defensa y garantía de los Derechos Humanos protegen la dignidad humana puesto que, en definitiva, ellos representan la manifestación expresa de la dignidad humana en las diferentes facetas y etapas del desarrollo de todo ser humano como persona ${ }^{39}$.

b) Y, si contemplamos cualquiera de las declaraciones específicamente formuladas para atender los problemas surgidos en el campo de las in- 
vestigaciones y las tecnologías biomédicas, constataremos la presencia y la trascendencia que, en toadas ellas, adquiere la dignidad humana. Por ejemplo, «La Declaración Universal sobre el Genoma Humano y los Derechos Humanos ${ }^{40}$ comienza con las siguientes palabras: "Recordando que en el Preámbulo de la Constitución de la UNESCO se invocan «los principios democráticos de la dignidad, la igualdad y el respeto mutuo de los hombres» y se impugna «el dogma de la desigualdad de los hombres y de las razas", se indica «que la amplia difusión de la cultura y la educación de la humanidad para la justicia, la libertad y la paz son indispensables a la dignidad del hombre y constituyen un deber sagrado que todas las naciones han de cumplir con un espíritu de responsabilidad y ayuda mutua",.... se declara que la Organización se propone alcanzar "mediante la cooperación de las naciones del mundo en las esferas de la educación de la ciencia y de la cultura los objetivos de la paz internacional y del bienestar general de la humanidad, para el logro de los cuales se han establecido las Naciones Unidas como proclama su Carta"4l.

$Y$, después de adherirse a los principios universales de los Derechos Humanos y a todas las Declaraciones y Pactos que los reconocen ${ }^{42}$ sigue diciendo en el párrafo cuarto del Preámbulo: "Teniendo presente también el Convenio delas Naciones Unidas sobre diversidad Biológica de 5 de junio de 1992 y destacando a este respecto que el reconocimiento de la diversidad genética de la humanidad no debe dar lugar a ninguna interpretación de tipo social o político que cuestione la «dignidad intrínseca y (...) los derechos iguales e inalienables de todos los miembros de la familia humana", de conformidad con el Preámbulo de la Declaración Universal de Derechos Humanos". En los párrafos dos y tres de la Declaración Universal sobre el Genoma Humano se realiza una larga enumeración de todos las Declaraciones, Pactos y Convenios de ámbito internacional sobre Derechos Humanos que son asumidos y tenidos en cuenta por esta Declaración.

Y una después de reconocer «que las investigaciones sobre el genoma humano y sus aplicaciones abren inmensas perspectivas de mejora- 
miento de la salud de los individuos y de toda la humanidad» destaca que tales investigaciones $\propto$ deben respetar plenamente la dignidad, la libertad y los derechos de la persona humana» estableciendo al mismo tiempo ala prohibición de toda forma de discriminación fundada en las características genéticas ${ }^{43}$. Dos cosas deben resaltarse en el texto precedente. Por un lado se impone a las investigaciones el deber de respetar plenamente la dignidad humana y la prohibición expresa de determinados tipos de discriminación por razones genéticas, como, por ejemplo, la discriminación laboral, o la exclusión en la contratación de pólizas de seguros de enfermedad o pólizas de seguros de vida. Adviértase la trascendencia que tiene, para eliminar este tipo de discriminaciones, el derecho a la intimidad de los datos genéticos y de las historias clínicas.

Tal es la importancia que se concede a la dignidad humana que a ella se dedica todo el apartado A, el primero de la Declaración, bajo el epígrafe «Dignidad humana y el Genoma Humano. "El genoma humano -comienza diciendo su articulado- es la base de la unidad fundamental de todos los miembros de la familia humana y del reconocimiento de su dignidad intrínseca y su diversidad. En sentido simbólico, el genoma humano es el patrimonio de la humanidad"44. Resulta curioso, -por no decir desconcertante-, que, cuando un bien material, por su valor cultural o artístico, se declara patrimonio de la humanidad, se protege hasta el punto de declararlo intocable, intangible, no manipulable ni modificable por intereses particulares o comerciales y que no se de, o se discuta al menos, igual tratamiento a este patrimonio, el más auténtico, importante y genuino patrimonio de la humanidad que es su propio genoma. Por ello, el reconocimiento del genoma como patrimonio de la humanidad, patrimonio que afecta al reconocimiento y garantía misma de la dignidad intrínseca humana, adquiere vital importancia, expresada en los dos párrafos que siguen: a) "Cada individuo tiene derecho al respeto de su dignidad y derechos, cualquiera que sean sus características genéticas" y b) "Esta dignidad impone que no se reduzca a los individuos 
a sus características genéticas y que se respete el carácter único de cada uno y su diversidad"45. En este texto se encuentran, sin duda, aunque de manera muy sintetizada, los caracteres de la personalidad, a saber: la individualidad y la diversidad, dentro de la unidad genérica humana ${ }^{46}$.

c) El Convenio de Bioética del Consejo de Europa, para la protección de los Derechos Humanos y la dignidad del ser humano con respecto a las aplicaciones de las Biología y la Medicina ${ }^{47}$, en su Preámbulo dice así: "Convencidos de la necesidad de respetar al ser humano a la vez como persona y como perteneciente a la especie humana y reconociendo la importancia de garantizar su dignidad"; "Conscientes de las acciones que podrían poner en peligro la dignidad humana mediante una práctica inadecuada de la biología y la medicina".

Tal preocupación subyace en todo el Convenio y es, sin duda, la causa que ha movido a los Estados a la aprobación del mismo, en el convencimiento de que hoy, más que nunca es necesario garantizar y proteger la dignidad humana frente a los inciertos caminos que pueden tomar algunos investigadores. De aquí que establezca con toda claridad que "Las Partes en el presente Convenio protegerán al ser humano en su dignidad y su identidad y garantizarán a toda persona, sin discriminación alguna el respeto a su integridad y a sus demás derechos y libertades fundamentales con respecto a las aplicaciones de la Biología y la Medicina." 48 .

En el artículo dos se establece la primacía del ser humano: "El interés y el bienestar del ser humano -se dice- deberán prevalecer sobre el interés exclusivo de la sociedad y de la ciencia". Pero icómo se establece tal primacía? Sin duda mediante el respeto a la dignidad de todo ser humano.

d) La Carta de Derechos Fundamentales de la Unión Europea ${ }^{40)}$ se establece que "la Unión está fundada sobre los valores individuales y universales de la dignidad humana, la libertad, la igualdad y la solidaridad y... sitúa a la persona en el centro de su actuación". Adviértase que sitúa como primer soporte del fundamento de la Unión Europea a la dig- 
nidad individual y colectiva. Y termina el preámbulo afirmando que la Unión reconoce los principios y derechos enunciados a continuación , para comenzar, una vez más, en el Capítulo primero dedicado a «la DIG$N I D A D$, con las siguientes palabras: "La dignidad humana es inviolable. Será respetada y protegida" ${ }^{\circ 50}$. No se puede decir más sobre la dignidad en tan pocas palabras: «es inviolable», «será respetada» y «será protegida».

No es posible seguir analizando otros muchos textos coincidentes en el reconocimiento de la trascendencia de la dignidad humana. Quiero, no obstante, para finalizar este apartado, recordar un texto tomado del Nuevo Código de Ética y Deontología Médica. Dice así: "La profesión médica está al servicio del hombre y de la sociedad. En consecuencia, respetar la vida humana y la dignidad de la persona y el cuidado de la salud del individuo y dela comunidad, son los deberes primordiales del médico"51

3. PERSONA, DIGNIDAD HUMANA E INVESTIGACIONES MÉDICAS.

3.1 LA LIBERTAD DE INVESTIGACIÓN COMO DERECHO FUNDAMENTAL ${ }^{52}$.

La libertad de investigación, como corolario de la libertad de pensamiento ${ }^{53}$ está expresamente reconocida en la Declaración Universal de Derechos Humanos: "Todo individuo tiene derecho a la libertad de opinión y de expresión; este derecho incluye el de no ser molestado a causa de sus opiniones, el de investigar y recibir información y opiniones y el de difundirlas, sin limitación de fronteras, por cualquier medio de expresión"54. Por otra parte en la misma Declaración se reconoce que «Toda persona tiene derecho .... a participar en el progreso científico y en los beneficios que de él resulten ${ }^{55}$.. En efecto, "la libertad de investigación es un derecho humano fundamental que debe ser respetado también en el campo de la ingeniería, por muy problemático que este pueda llegar a ser $^{256}$. Estoy de acuerdo con estas palabras de Diego GraCIA, y también 
en que -como él mismo sigue escribiendo- debe existir un control estatal "en aquellos casos en que la investigación pueda afectar a los derechos de las demás personas" los derechos de las «personas», cuya apreciación no es baladí, pues las personas son precisamente los sujetos de los derechos humanos, y no tendría sentido admitir el ejercicio de derechos que atenten contra los derechos de otras personas.

Ciertamente es importante resaltar la libertad de investigación. Así lo reconocen actualmente todas las Declaraciones de Derechos y las Constituciones democráticas -así lo reconoce, por ejemplo, el artículo 20.1 de la Constitución española-. Pero debe analizarse, en todo caso, a la luz de los problemas éticos y jurídicos que plantea el derecho fundamental a la investigación y producción científica y técnica, especialmente en el ámbito de las investigaciones médicas y, de manera especial, en cuanto se refiere a la manipulación e ingeniería genética en seres humanos. El reconocer la trascendencia e importancia del derecho a la libertad de investigación científica no justifica, en modo alguno, que pueda convertirse en fuente de lesión de otros derechos humanos. En palabras de Peces-Barba, refiriéndose al Proyecto Genoma Humano, “... un logro científico que supone tanto para la cultura de nuestro tiempo y para el futuro no puede a su vez, en determinados casos, convertirse en un peligro para la persona y sus derechos, por lo que genera a su vez la necesidad de nuevas protecciones y nuevos derechos" ${ }^{258}$. Es cierto que, en virtud del derecho de libertad, todos los hombres tienen, en principio, derecho a hacer todas aquellas cosas que no invadan la libertad de los demás o que no violen sus derechos. Pero alguien tiene que hacer de árbitro de estas fronteras. Es el Estado el que tiene que regular los límites y las condiciones del ejercicio de la libertad.

\subsection{LA LIBERTAD DE INVESTIGACIÓN Y SUS LÍMITES.}

En efecto, ningún derecho es absoluto. Es decir, todo derecho es limitable cuando existan razones fundas para ello. Y ninguna otra razón 
aconseja tanto limitar la investigación científico-médica -especialmente si esta ha de llevarse a cabo sobre los propios cuerpos (seres) humanos- como aquellas investigaciones que puedan suponer un atentado a la integridad física o moral e incluso un atentado a la propia vida de seres humanos, es decir, de personas humanas. Los derechos de los demás, especialmente el de la vida y el de la integridad física y moral u otros derechos como el de la intimidad de los datos biomédicos, suponen un límite a derechos que generen riesgos de destrucción de la vida humana. Porque si no existe la vida, si se destruye, se aniquilan al mismo tiempo todos los demás derechos.

¿Qué sucede cuando como consecuencia de la investigación, de las prácticas médicas, de la manipulación y la ingeniería genética se producen daños o perjuicios para los individuos o para toda la humanidad? ¿Estará justificada tal investigación? En principio no parece estar amparada por la Declaración Universal de Derechos Humanos. Recuérdese que la Declaración habla de beneficios ${ }^{59}$ dando por supuesto que, si no se producen beneficios no tiene sentido la investigación, porque el derecho a la libertad de investigación sólo se justifica por el principio de beneficencia o al menos de no-maleficencia pero el derecho a la investigación nunca podrá atentar contra otros derechos fundamentales de la persona. Así queda patente en la propia Declaración Universal de Derechos Humanos: "En el ejercicio de sus derechos y en el disfrute de sus libertades, toda persona estará solamente sujeta a las limitaciones establecidas por la ley con el único fin de asegurar el reconocimiento y el respeto de los derechos", derechos y libertades que «... no podrán en ningún caso ser ejercidos en oposición a los propósitos y principios de las Naciones Unidas ${ }^{60}$. Y mucho más claro es a este respecto el artículo 30 : * Nada en la presente Declaración - dice- podrá interpretarse en el sentido de que confiere derecho alguno al Estado, a un grupo o a una persona, para emprender o desarrollar actividades o realizar actos tendentes a la supresión de cualquiera de los derechos y libertades proclamados en esta Declaración". 
Según esto, ninguna actividad científica será justificable si atenta contra los derechos humanos o de su práctica se sigue la agresión o supresión los derechos de las personas. Y es que, en la actualidad, se corren serios riesgos de que el exceso de ambición por obtener resultados científicos, aun a costa de la propia vida de seres humanos o de su integridad física y moral, atente contra la propia dignidad humana, que es el fundamento de todos los derechos humanos. "Ciertamente -escribe Ángela APARISI-, los científicos han disfrutado durante siglos de un alto grado de autonomía. En escasas ocasiones se han impuesto controles externos a su actividad. Sin embargo, al menos en el ámbito de la intervención en el genoma humano, parece que este principio de absoluta libertad e independencia es actualmente insostenible. Se trata de un derecho que no es absoluto, sino que posee límites. Existen otros derechos derivados de la dignidad humana, que no sólo pueden, en determinadas circunstancias, limitar la libertad de investigación, sino que deben hacerlo. No se trata en absoluto de negar el derecho, pero sí de ponderar los intereses en juego, constatar la existencia, en determinados casos, de un conflicto de derechos y la necesidad de jerarquizarlos" 61 .

¿Y cuando se entiende que existe una agresión o destrucción de la dignidad humana? La propia Declaración entiende que cuando se violan los Derechos en ella proclamados. Se atenta contra la dignidad humana cuando se destruye la propia vida humana o cuando se viola la libertad o la seguridad de su persona. Se atenta contra la dignidad humana cuando se somete a seres humanos a esclavitud o servidumbre, cuando se comercia con seres humanos adultos como esclavos, cuando se destruyen embriones humanos recién engendrados, cuando se comercia con tejidos humanos o con los resultados de la investigación sobre el genoma humano, por pertenecer al patrimonio de toda la humanidad; cuando se somete a torturas o a penas y tratos crueles, inhumanos y degradantes a cualquier persona humana ${ }^{62}$. Se atenta contra la dignidad humana cuando se invade arbitrariamente la vida privada, el domicilio la correspondencia, la familia, la intimidad de las per- 
sonas; cuando sè impide el ejercicio de la libertad de pensamiento, de cultura o de religión; cuando se persigue políticamente a ciudadanos y no se les da cobijo o asilo; cuando se impide o no se proporciona a los individuos los medios indispensables para una subsistencia digna; cuando se les explota o se discrimina en el trabajo o en salario; cuando no se le proporciona el acceso a la educación, a la salud a una vivienda y tiene que vivir en condiciones infrahumanas.

Es evidente que de las investigaciones médica se derivan enormes beneficios para la salud de las personas, pero no cabe duda que del ejercicio de la investigación científico-medica, que reiteramos es un derecho fundamental, pueden derivarse también resultados contrarios o maledicentes que atentan contra los derechos de algunas personas, poniendo en entredicho la dignidad humana. En tales casos el Estado podrá limitar el ejercicio de la libertad de investigación, de acuerdo el artículo 19 del Pacto Internacional de Derechos Civiles y Políticos (siempre que se pongan en peligro los derechos de los demás o cuando el bien público así lo exija. En consonancia con este texto, y con el citado anteriormente de la Declaración Universal de Derechos Humanos, que imponen una limitación fundamental al ejercicio de los Derechos Humanos, la Constitución Española, después de reconocer la libertad de pensamiento y de opinión así como el derecho a la producción y creación literaria, artística, científica y técnica ${ }^{63}$ establece que "estas libertades tienen su límite en el respeto a los derechos reconocidos en este Título, en los preceptos de las leyes que lo desarrollen y, especialmente en el derecho al honor, a la intimidad, a la propia imagen..."64

Pero ¿quien está legitimado para poner los límites? ¿El individuo, el propio científico, el Estado?. Habitualmente se dice que los límites los establece el Estado para proteger los derechos de los demás o por razones de bien público. Así se desprende de gran parte de las Declaraciones y Convenios que confieren a los Estados Partes tanto la obligación de reconocer y garantizar los Derechos como la potestad de limitarlos, cuando los conflictos entre derechos así lo aconsejen. Sin embargo en la 
actualidad, el ámbito de las investigaciones médicas y de la ingeniería genética se ha desbordado traspasando las fronteras de los Estados. EI problema se ha generalizado adquiriendo una dimensión universal de tal gravedad y trascendencia que ninguna de estas instancias puede decidir por sí sola. Es la Humanidad entera, la Comunidad Internacional políticamente organizada la que tiene que vigilar, decidir, permitir o prohibir, regular en definitiva, las condiciones y el alcance del derecho a la libertad de investigación, para que, en todo momento, tanto en la teoría como en la práctica, se respete la dignidad del hombre, no sólo en su estadio individual sino también como colectivo. Pues como dice Diego GrACIA "el problema de la investigación genética afecta a algo que, como la UNESCO ha proclamado reiteradamente, es spatrimonio de la Humanidad», y por tanto debe ser decidido por el conjunto de los afectados, que somos todos. Esto obliga a plantear los problemas éticos de la ingeniería genética en un orden escalar distinto al que estamos habituados, el de la Humanidad entera, presente y futura"65.

¿Qué significa esto?. Significa poner en duda la legitimidad de los Estados nacionales para tomar decisiones en este tipo de problemas. Significa que tal vez el Estado esté deslegitimado, para señalar directrices éticas o dictar normas jurídicas en una materia que desborda. "El tema no es nuevo, ni lo ha planteado por vez primera la ingeniería genética. Fueron las armas nucleares las que hicieron evidente la falta de legitimidad de los Estados nacionales para producir armas que directa o indirectamente amenazan al conjunto entero de la Humanidad, y plantearon la necesidad de una entidad supranacional con poder suficiente para controlar su investigación y desarrollo. Durante los años cuarenta fue frecuente la apelación a un agobierno mundial» como único modo de afrontar de modo racional el problema planteado por las armas nucleares" $"$. Al Estado le compete, eso sí la obligación de velar, en su ámbito territorial, para que, en el ejercicio del derecho a la libertad de investigación se respeten todos los Derechos Humanos que puedan entrar en colisión. Una pauta para lograr el equilibrio entre todos estos dere- 
chos la encontramos precisamente en la Carta de los Derechos Fundamentales de la Unión Europea que, después de reconocer el derecho a la vida y rechazar la pena de muerte, establece el derecho a la integridad física y psíquica de la persona. $\mathrm{Y}$, en el marco de las investigaciones médicas y de la biología, afirma que se respetarán en particular: "el consentimiento libre e informado de la persona de que se trate, de acuerdo con las modalidades establecidas en la ley; la prohibición de las prácticas eugenésicas, y en particular las que tienen por finalidad la selección de las personas; la prohibición de que el cuerpo humano o partes del mismo en cuanto tales se conviertan en objeto de lucro; la prohibición de la clonación reproductora de seres humanos"6?

Para comprender el alcance del derecho a la libertad de investigación y sus relaciones con los derechos y libertades de fundamentales y con la dignidad de todo ser humano es imprescindible analizar la Declaración sobre el genoma humano. En su Preámbulo recuerda las Resoluciones de las Naciones Unidas $22 \mathrm{C} / 13.1,23 \mathrm{C} / 13.1,24 \mathrm{C} / 13.1,25 \mathrm{C} / 5.2,25$ $\mathrm{C} / 7.3,27 \mathrm{C} / 5.15,28 \mathrm{C} / 2.1$ y $28 \mathrm{C} / 2.2$ en las cuales se insta a la UNES$\mathrm{CO}$ a promover y desarrollar la reflexión ética y las actividades conexas en lo referente a las consecuencias de los progresos científicos y técnicos en el campo de la biología y la genética, respetando los derechos y las libertades fundamentales del ser humano. Y, ya en el articulado se reconoce que "... la investigación está encaminada a redundar en beneficio de la salud de otras personas pertenecientes al mismo grupo de edad o que se encuentren en las mismas condiciones genéticas, a reserva de que dicha investigación se efectúe en las condiciones previstas por la ley y sea compatible con la protección de los derechos humanos ${ }^{68}$." Y reconoce también que "Nadie podrá ser objeto de discriminaciones fundadas en sus características genéticas, cuyo objeto o efecto sería atentar contra sus derechos humanos y libertades fundamentales y el reconocimiento de su dignidad" $"$ ".

Pero, por cuanto se refiere al tema que estamos tratando, el contenido realmente importante se encuentra en los apartados C y D de la De- 
claración. El primero se refiere a las Investigaciones sobre el genoma humano y resalta de manera especial el respeto a los derechos humanos y la dignidad humana en todas las investigaciones biomédicas. Este apartado está integrado por los artículos 10, 11 y 12, que, dada la importancia y riqueza de su contenido reproducimos casi literalmente:

Artículo 10: "Ninguna investigación relativa al genoma humano ni ninguna de sus aplicaciones, en particular en las esferas de la biología, la genética y la medicina, podrá prevalecer sobre el respeto de los derechos humanos, de las libertades fundamentales y de la dignidad humana de los individuos o, si procede, de grupos de individuos".

Artículo 11: "No deben permitirse las prácticas que sean contrarias a la dignidad humana, como la clonación con fines de reproducción de seres humanos". A tal efecto -sigue diciendo el mismo artículo "Se invita a los Estados y a las organizaciones internacionales competentes a que cooperen para identificar estas prácticas y a que adopten en el plano nacional o internacional las medidas que corresponda, para asegurarse de que se respetan los principios enunciados en la presente Declaración."

En el artículo 12. b) se afirma que "La libertad de investigación, que es necesaria para el progreso del saber, procede de la libertad de pensamiento. Las aplicaciones de la investigación sobre el genoma humanos, sobre todo en el campo de la biología, la genética y la medicina, deben orientarse a aliviar el sufrimiento y mejorar la salud del individuo o de toda la humanidad".

Sin embargo, aunque la Declaración reconoce en el artículo 12. a) que "Toda persona debe tener acceso a los progresos de la biología, la genética y la medicina en materia de genoma humano"este derecho ha de ejercitarse siempre "respetándose su dignidad y derechos", es decir respetando la dignidad y los derechos de toda persona, lo que quiere decir que la dignidad humana se antepone siempre a cualquier tipo de investigación biomédica, pues ninguna investigación puede violar la dignidad humana ni los derechos que le son inherentes, tal como reiteran todas las Declaraciones y Pactos sobre Derechos Humanos. 
El apartado D de la Declaración Universal sobre el Genoma Humano establece las condiciones en que debe llevarse a cabo el ejercicio de la actividad científica. En este sentido la propia Declaración en su artículo 13 entiende que "Las consecuencias éticas y sociales de las investigaciones sobre el genoma humano imponen a los investigadores responsabilidades especiales de rigor, prudencia, probidad intelectual e integridad, tanto en la realización de sus investigaciones como en la presentación y utilización de los resultados de éstas..." Y, a tal fin, la propia Declaración establece en su artículo 15 que "Los Estados tomarán las medidas apropiadas para fijar el marco del libre ejercicio de las actividades de investigación sobre el genoma humano respetando los principios establecidos en la presente Declaración, a fin de garantizar el respeto a los derechos humanos, las libertades fundamentales y la dignidad humana..." Y "velarán por que los resultados de estas investigaciones no puedan utilizarse con fines no pacíficos".

Téngase en cuenta que aquí la referencia a fines pacíficos (la paz) puede entenderse de diferentes formas. No es admisible la investigación biológica para crear armas bacteriológicas de destrucción masiva. Hoy la Humanidad no puede consentir este ataque a la paz mundial en nombre del progreso y del derecho a la libertad de investigación científica pues una ciencia capaz de destruir a la humanidad no puede considerarse ni un derecho y ni siquiera progreso ${ }^{70}$. Pero también puede entenderse la paz en un segundo sentido. La paz intelectual. No sería lógico ni coherente que una investigación génica y biotecnológica, situada al borde (o en la frontera) de la posible violación de la dignidad de la persona y de sus Derechos Humanos Fundamentales pueda crear una tensión y división científica o ideológica de imprevisibles consecuencias. ¿Se habla de pactos y de consensos?. Nada habría más útil que un gran pacto ético y jurídico, un gran consenso, reflejado en pactos internacionales, sobre el derecho y la libertad a la investigación y los límites éticos y jurídicos a que deben estar sometidos los procesos de tal investigación, evaluando, en cada momento, los riesgos y ventajas de los 
resultados, para prevenir los abusos. Deben establecerse, hasta donde sea posible los límites de la investigación y el respeto a los derechos humanos y la dignidad de las personas. Al fin y al cabo entiendo que ésta es la única barrera de la investigación científica: el respeto a todos los Derechos Humanos porque sólo respetándolos, todos, podremos afirmar que los seres humanos viven con dignidad. Para lograr el consenso al que acabo de referirme los Estados, al mismo tiempo que deben tomar las medidas adecuadas para el fomento de la investigación en materia de bioética, exigirán a cada uno de sus miembros las responsabilidades ante las cuestiones fundamentales relacionadas con la defensa de la dignidad humana que puedan plantear la investigación en biología, genética y medicina y las correspondientes aplicaciones.Y deberían comprometerse también a favorecer al respeto un debate abierto en el plano internacional que garantice la libre expresión de las distintas corrientes de pensamiento socioculturales, religiosas y filosóficas ${ }^{71}$. Y es que, hoy más que nunca, ante la reiterada pregunta acerca de si éticamente puede hacer todo aquello que técnicamente es posible no cabe mas que una respuesta: diálogo. Es necesario establecer un diálogo entre la medicina, la filosofía (ética), la teología y el derecho ${ }^{72}$. En un momento en que la sociedad universal está desorientada por los cambios radicales que están produciéndose en la propia realidad humana, como consecuencia de los nuevos e impresionantes descubrimientos de la moderna biotecnología, es más necesario que nunca este diálogo intercultural, que permita a los teólogos y filósofos comprender el alcance y los beneficios de los resultados de la investigación científica y de la práctica médica, y a los científicos e investigadores se dejen iluminar por los principios éticos y jurídicos de los expertos en estas disciplinas. Sólo con el diálogo y el entendimiento lograremos el consenso y la paz entre ética, ciencia y derecho.

La protección de los derechos humanos y de la dignidad del ser humano con respecto a las aplicaciones de la Biología y la Medicina está garantizada en el Convenio de Asturias sobre Derechos Humanos y Bio- 
medicina que ya hemos citado con anterioridad. En él se dice: "La investigación científica en el ámbito de la biología y la medicina se efectuará libremente, a reserva de lo dispuesto en el presente Convenio y en otras disposiciones jurídicas que garanticen la protección del ser humano"73.

Digamos para terminar que el derecho a la libertad de investigación es un derecho fundamental que el científico ejerce libremente sin más límites que el respeto a los derechos humanos consagrados en las Declaraciones Universales de Derechos Yo diría que el único límite a la investigación científica es precisamente la dignidad de las personas, entendiendo por persona todo individuo de la especie humana. Ciertamente "la excelencia del hombre, el alto valor proporcionado a la grandeza de su ser constituye el secreto para discernir lo permisible de lo censurable. El respeto y promoción de la persona, el carácter inviolable de su dignidad, son los límites infranqueables de la acción, la frontera insalvable de las técnicas aplicables a la vida humana"74. 
1 El presente trabajo es una reproducción del texto de la conferencia impartida el día 13 de noviembre de 2002 en el marco de las Jornadas sobre Bioética y Derecho que se desarrollaron en el Centro Asociado de la UNED de Melilla. He de advertir también que este artículo refleja, en parte, algunas de las reflexiones expuestas en mi conferencia titulada "Persona, Derecho y Dignidad Humana" que fue impartida en La Coruña el día 15 de julio de 2002, en el marco del curso de verano, que yo mismo dirigí, titulado "Investigaciones médicas, Derecho y Dignidad Humana". Las ponencias de dicho curso están en curso de publicación en un libro que aparecerá en 2003 en la Editorial COMARES de Granada con el título Biotecnologia, Derecho y Dignidad Humana", obra que, por la calidad de los ponentes que en ella participan, recomiendo a todos cuantos estén interesados en estos temas.

2 "La biomedicina del futuro". Revista de la Fundación de Ciencias de la Salud, año 1999. $\mathrm{N}^{\circ} 2$; Véase *Editorial, pg. 4

3 El proyecto "Genoma Humano se inició en 1990. Este proyecto se ha desarrollado fundamentalmente $-\mathrm{y}$ siguen sus investigaciones- en Estados Unidos, Francia, Gran Bretaña, Alemania y Japón. No obstante cabe advertir que también han participado en el Proyecto investigadores de otros países. En este sentido hay que destacar la figura del científico español D. Santiago Grisolía que, durante mucho tiempo, ha sido el Presidente de la Comisión de la UNESCO del Proyecto Genoma Humano. Su objetivo ha sido conseguir la secuencia del Genoma Humano y, aunque, según la planificación inicial, se preveía finalizarlo en el año 2005. los rápidos avances en la investigación han permitido avanzar los primeros resultados en julio del pasado año 2001. Evidentemente las investigaciones continúan. A purtir de ahora comienza la aplicación de los resuliudos científicos a la medicina y a la biotecnologia. Para aproximarse al conocimiento del Proyecto Cenoma Humano, entre la abundante bibliografía existente puede verse: En primer lugar "La Declaración Universal sobre el Genoma Humano y los Derechos Humanos" de la UNESCO, 1997; APARISI MIRALLES, Ángela, "El Proyecto Genoma Humano: algunas reflexiones sobre sus relaciones con el Derecho", Tirant to Blanch, Valencia 1997; BLÁZQUEZ RUIZ, Javier, "Derechos Humanos y proyecto Genoma",Editorial Comares, Granada ,1999: LEE, Thomas F., El Proyecto Genoma Humano", Gedisa Editorial, Barcelona 2000 (traducción de José A. ÁLVAREZ; Revista de "Derecho y Genoma Humano", Fundación BBV, Bizkaia.

4 XAVIER ESTIVILL es Director de Instituto de Investigación Oncológica (1.R.O.), Departamento de Genética Molecular del Hospital Durán i Reynals de Barcelona. Véase su artículo "Medicina genómica" en Revista de la Fundación de Ciencias de la Salud, cit.. pgs. 6-11.

5 Resulta inagotable la bibliografia generada en los últimos años en torno a los problemas de la vida humana y especialmente de la revolución que ha supuesto la posibilidad de la fecundación -in vitro * con cuantos beneficios y temores suscita a la vez. Citemos algunos libros que pueden orientarnos y aclarar nuestras dudas al respecto: ABEL, F., BONE. E. y HARVEY J. C., Edits. "La vida humana: Origen y desarrollo (Reflexiones bioéticas de científicos y moralistas)", U. De Comillas (Madrid) e Instituto Borja de Bioética (Barcelona ), 1989;RODRÍGUEZ LLÑ̃, A. y LOPEZ MONDÉJAR, R. . "La fecundación -in vitro.", Ediciones Palabra, Madrid 1986 MONGE, Fernando, Persona Humana y Procreación Artificial" Ediciones Palabra, Madrid 1988; ZaRRALUQUI, Luis, "Procreacion asistida y Derechos Fundamentales" Edit. Tecrios, Madrid 1988; 
DEXEUS TRIAS DE BES, José M., “Nacer hoy" ((Discurso de recepción en la Real Academia de Medicina de Cataluña), Barcelona 1995; JLNQUERA DE ESTÉFANI, Rafael, "Reproducción asistida, .Filosofia Ética y Filosofia Juridica", Ed. Tecnos, Madrid, 1998; GARCÍA MAURIN̄O, José María, "Nuevas formas de reproducción humana", San Pablo, 1998; FERNÁNDEZ DE LUJAN, Federico, "La Vida Principio Rector del Derecho", Dykinson, Madrid 1999; SCOLA, Ángelo, "QQué es la vida?", Ediciones Encuentro, Madrid 1999; JUNQUERA DE ESTÉFANI,Rafael , "El embrión humano: una realidad necesitada de protección", Revista Genoma Humano, $N^{\circ} 12$ Enero-Junio 2000, pg.s. 31-45; AA. VW. "El destino de los embriones congelados", Fundación Universitaria Española, Madrid 2003.

6 Pueden verse los estudios realizados por la Asociación Española de Derecho Sanitario, recogidos en las publicaciones de la Fundación MAPFRE MEDICINA, especialmente los referidos al IV, V, VI y VII Congresos Nacionules de DERECHO SANITARIO, correspondiente a los años 1998, 1999, 2000 y 2001.

7 Véasc AA. VV. "Biotecnología" Fundación Universitaria San Pablo CEU, Madrid, 1986; LACADENA Juan R., GRACIA Diego, VIDAL Marciano y ELIZAR F. Javier, "Manipulación genética y moral cristiana", Fundación Universitaria San Pablo CEU, Madrid 1988; SÄSNCHEZ MORALES, Maria R. Impactos sociales de la Biotecnología", UNED, 1996; GAFO Javier, Editor, "Fundamentación de la Bisética y Manipulación Genética"

Publicaciones de la U. Pontificia de Comillas, Madrid, 1998; GAFO Javier, Editor, Ética y Biotecnología", Publicaciones de la $\mathrm{C}$. Pontificia de Comillas, Madrid, 1993; VECA GUTIËRREZ y OTROS, "Experimentación Humana en Europa", Universidad de Valladolid, 1997
8 Véase LÓPEZ GLZMAN, J., "Objeción de conciencia farmacéutica”, Ediciones Internacionales Universitarias, Barcelona, 1997; LÓPEZ GUZMÁN José y APARISI Ángela, "Deontología farmacéutica", EUNSA, Pamplona, 2000.

9 DE REMIRO VELÄZQUEZ, Francisco, " $\mathrm{La}$ eutanasia y la humanización de la medicina", Gráficus Andrés Martín, Valladolid, 1991;POLLARD BRAIAN, "Eutanasia", Ediciones RIALP, Madrid, 1991; VICO PEINADO José, "Dolor y muerte humana digna", San Pablo, Madrid , 1995; CONFERENCIA EPISCOPAL ESPAÑOLA, "La eutanasia" Ediciones Paulinas, Madrid, 1993; OLLERO Andrés, "Derecho a la vida y derecho a la muerte", Ediciones RIALP, Madrid, 1994;GARCÍA-MAURIÑOJ. María, "Otras formas de morir", San Pablo, Madrid, 1998 ; HURTADO OLIVER Javier, "El de Derecho a la vida éy a la muerte?", Editorial Porrúa, México, 1999; MARCOS DEL CANO Ana María, "La Eutanasia (Estudio filosóficojuridico)”, UNED y Marcial Pons, Barcelona, 1999;"Eutanasia, Ayuda al suicidio y profesionales de la medicina", Revista Cuadernos de Bioética, $\mathbf{N}^{\circ} 44$, Santiago de Compostela, 2001

10 Citaremos algunos escritos entre las innumerables obras que han visto la luz en los últimos años del siglo $\mathrm{XX}$ y primeros del siglo $\mathrm{XXI}$ : "Biología, desarrollo científico y ética", Fundación Valenciana de Estudios Avanzados, 1986; MARTÍN MATEO Ramón, "Bioética y Derecho", Aricl, Barcelona, 1987; GUY DURAND, "La bioética”,Edit. Desclée, Bilbao 1992; VIDAL Marciano, "Moral de la persona y Bioética Teológica", Editorial P. S., Madrid, $8^{a}$ edc. 1991 (Existen ediciones posteriores); HERRAVZ Gonzalo, "Comentarios al Código ético y Deontología médica", EUNSA, Pamplona 1992; ROMEO CASABONA Carlos María, "El Derecho y la Bioética ante los límiles de la vida humana", Centro de Estudios 
Ramón Areces, Madrid 1994; BLÁZQUEZ

Niceto, "Bioética Fundamental", Biblioteca de Autores Cristianos, Madrid 1996; AA VV. "Materiales de Bioética y Derecho" (Edic. a cargo de María CASADO), Cedecs Editorial, Barcelona 1996; ALBURQUERQUE Eugenio, Bioética (Una apuesta por la vida)", Editorial CCS, $3^{a}$ edic., Madrid 1997; FEITO GRANDE Lydia, Edit., "Estudios de bioética", Dykinson, Madrid 1997; ANDORNO Roberto, "Bioética y dignidad de la persona", Edit. Tecnos, Madrid 1998; DEL BARCO José Luis, "Bioética de la Persona", Universidad de la Sabana, Colombia, 1998; MASIÁ CLAVEL Juan, "Bioética y Antropologia", Comillas, 1998; HERNÁNDEZ ARRLAGA José Luis, "Ëtica en la investigación biomédica", Edit. El Manual Moderno, México, 1999; AA.VV (Coordinación de Marcelo PALACIOS), "Bioética 2000", Ediciones NOBEL, Oviedo, 2000.

11 Gómez Sancho, Marcos (Presidente del Colegio de Médicos de las Palmas), Los cuidados paliativos en V Congreso de Derecho Sanitario, Fundación Mapfre Medicina, Madrid 1999, pg. 129

12 Para la construcción del concepto de persona, entre la abundantísima bibliografía existente, por tratarse de una cuestión siempre problemática, sugerimos las siguientes lecturas: ANDORNO, Roberto: Bioética y dignidad humana, Tecnos, Madrid, 1998; Díaz, C., Para ser persona, Instituto Emmanuel Mounier, Las Palmas 1993; MORENo VILLA, .I., voz PERSONA en Diccionario de Pensamiento Contemporáneo, edt. San Pabloo, Madrid, 1997; Moreno Villa, M., El hombre como persona , Caparrós, Madrid, 1995; Marrtain, J., Para una filosofia de la persona humana, Club de lectores, Buenos Aires 1973; Mocinien, J., Le personnalisme, PUF, Paris, 1951. Hemos consultado también la extensa y magnífica obra coordinada por Lain EnTralco y eserita por un excelente equipo de colaboradores entre los que destacan Ignacio EL.LACURí,
Diego Gracia Gullatén, José Ma López Piñero, José $\mathrm{L}$. PESET, etc., editada en once volúmenes con el útulo Persona y comunidad: FilosofiaSociología-Medicina; MARTÍNEZ MORANarciso, "Persona, Dignidad Humana e Investigaciones Médicas" (en prensa) en la obra Biotecnología, Derecho y Dignidad Humana, Editorial Comares, Granada, 2003

13 BoEclo, .De persona et duabus naturiss, c. 3 , Patrologie Latine, t. 64, col. 1343.

14 Voz Dignidad, Diccionario de la Lengua Española, Real Academia Española, vigésima segunda edición, Espasa, 2001, Vol. 1, pg. 823.

15 .Persona significat id quod est perfectissimum in tota natura, Santo TOḾs, Suma de Teología, I-I, q. 29 a. 3, Biblioteca de Autores Cristianos, Madrid, 1988, pg. 327

16 Ibidem, pg. 326.

17 Véase R. ANDorno, Bioética y dignidad de la persona, cit., pag. 63.

18 Sun Buenavenjura, II Sen. a. 2, q. 2 ad 1.

19 San Acustín, De Civitate Dei, XIX,, c. XIII, 2.

20 San Acustín, Ioannis Evangelium tractatus, 23, 6.

21 Mill.in Pufllis, Persona humana y justicia social, Madrid, 1973, pg.15.

22 Véase la Encíclica Quod Apostolici numeris, $\mathrm{n}^{\circ}$ 6.

23 Para delimitar estos conceptos con precisión véase el magnífico estudio, en el que nos apoyamos en esta parte de la exposición, de Morevo VilL.A, M., Dignidad de la persona en Diccionario de Pensamiento contemporáneo, cit. , pp.359-368.

24 Ibidem, pg. 361.

25 Un estudio amplio de la persona en E. KavT puede verse especialmente en dos de sus obras más representativas: Crítica de la razón práctica y Crítica del juicio, Espasa Calpe, Madrid, 1975 y 1977 respectivamente.

26 MORENo ViLL., M., cit. pg. 362. 
27 Ibidem, pg. 361.

28 ANDorio, R., Bioética y dignidad de la persona, cit. Véanse las páginas $42-44$ y $68-$ 69.

29 Para ccomprender mejor el problema que venimos analizande, desde el punto de vista filosófico, es recomendable la lectura del magnífico estudio de L. Lfisiz Lacavista, titulado Consideraciones sobre la dignidad de la persona y de la vida humana, Anales de la Real Academia de Ciencias Morales y políticas, num.53, 1976, pp. 17-41. Desde una perspectiva jurídica Pedro SrRM ha escrito un trabajo titulado La dignidad de la persona como principio del derecho público en Derechos $y$ Libertades, Revista del Instituto Bartolomé de las Casas, Año II, $\mathrm{N}^{\circ}$ 4, Universidad Carrlos III, Madrid 1995, pp. 287-306. El mismo autor ha escrito otro artículo, desde la perspectiva de la jurisprudencia, titulado Dignidad de la persona: un estudio jurisprudencial en Persona y Derecho (Estudios en homenaje al Prof. Javier Hervada - II), $N^{\circ}$ 41, Pamplona 1999, pp.139-196.

30 Es obvio que no podremos analizar todas las referencias que se hacen a la dignidad en multitud de Declaraciones, Pactos,

Recomendaciones, Directivas... etc. Menos aún sería posible efectuar un análisis del tratamiento de la dignidad humana en toda la legislación. Por ello he de limitarme a reflexionar brevemente sobre algunos textos más representativos. Para comprender de manera amplia y exhaustiva la dignidad humana en el derecho, desde todas las perspectivas, es fundamental el magnífico libro de Jesús GoNzÁlez PéRE:z titulado La dignidad humana, Civitas, Madrid, 1986.

31 Estas son las primeras pulabras del primer párrafo del Preámbulo de la Declaración Universal de Derechos Humanos de 10 de diciembre de 1948, la cual constituye el texto más importante en el ámbito de las Declaraciones de Derechos de todos los tiempos y sirve para informar e interpretar todos los textos (Declaraciones, Pactos, Constituciones...) en materia de Derechos Humanos. Así sucede en la Constitución española según reconoce el artículo 10.2 de la misma.

32 Véase el párrafo quinto del mismo Preámbulo de la Declaración Universal de Derechos Humanos.

33 Artículo $1^{\circ}$ de la Declaración Universal de Derechos Humanos

34 El artículo segundo de la Declaración quicre resaltar la igualdad en derechos y en dignidad de todos los hombres al no admitir ningún tipo o razón de discriminación.

35 Véanse más adelante, en esta misma obra, Los desafios juridicos de las biotecnologias en el umbral del siglo XXI de Carlos Romeo Casibova y Biotecnología y derechos humanos: presente y futuro de Benito DF. Castro CID.

36 Véanse en la obra colectiva coordinada por Narciso MARTÍNEZ MORÁN, "Biotecnología, Derecho y Dignidad Humana", Edit. COMARES, Granada (En prensa), 2003 los trabajos siguientes: "La necesidad de redefinir el embrión humano" de Íñigo II: MIGUEL Berlain ; "Las técnicas de reproducción humana asistida y la dignidad en el inicio de la vida" de Rafael JuxQ̨era 13: Estéfani; "El problema de la investigación con embriones $y$ células madre y la dignidad humana" de Natalia LOPEZ Morstalla y La clonación humana reproductiva de Marciano VIDAL. carcí.

37 Véase en la obra citada en nota anterior: "Dignidad humana en el final de la vida y cuidados paliativos" de Ana María Marcos DFi. Cano.

38 Véanse en la obra citada en las dos notas anteriores: "Propiedad y destino de los resultados de las investigaciones médicas" de Ricardo DE LORENzo Y MONTERo; "Derecho a la intimidad en el ámbito de la biomedicina"de 
Antonio Enrique PÉRez LuÑo y "El conflicto entre el derecho a la información y el derecho a la intimidad" de Cristina Martix Sanjlias.

39 La garantía de todos los Derechos Humanos, que constituyen la dotación y cl contenido de la dignidad humana, pude constatarse, por ejemplo, en el articulado del Pacto

Internacional de Derechos Civiles y Políticos de 1966, en el Pacto Internacional de Derechss Económicos, Sociales y Culturales, también de 1966 y en el Convenio Europeo para la Protección de los Derechos Humanos y de las Libertades Fundamentales, aprobado en Roma en 1950.

40 La Declaración Universal sobre el genoma Humano y los Derechos Humanos fué aprobada el 11 de noviembre de 1997 por la Asamblea General de la UNESCO (Organización de las Naciones Linidas para la Educación de la Ciencia y la Cultura).

41 Párrafo primero del Preámbulo de la Declaración Universal sobre el Genoma Humano y los Derechos Humanos

42 En los párrafos dos y tres de la Declaración Universal sobre el Genoma Humano se realiza una larga enumeración de todos las Declaraciones, Pactos y Convenios de ámbito internacional sobre Derechos Humanos que son asumidos y tenidos en cuenta por esta Declaración.

43 Véase el párrafo sexto del Preámbulo de la Declaración sobre el Genoma Humano...

44 Artículo uno de la Declaración sobre el Genoma Humano...

45 Artículo dos de la Declaración sobre el Genoma Humano...

46 También en el Apartado B, que constituye la segunda parte de la Declaración, se reitera la importancia de la dignidked humana al hablar de los derechos de las personas interesadas y afectadas pasivamente en la investigación. Liste Convenio fue aprobado en Oviedo el $4 \mathrm{de}$ abril de 1997 y es conocido como el Convenio de Asturias.

47 Este Convenio fue aprobado en Oviedo el $4 \mathrm{de}$ abril de 1997 y es conocido como el Convenio de: Asturias.

48 Articulo primero del Convenio de Bioética para la protección de los Derechos Humanos y In dignidad del ser humano. Es de destacar este Convenio el cl tema que estumos abordando porque se refiere directamente a la protección de la dignidad humana , de la persona humana y sus derechos, precisamente en el campo de las investigaciones hiomédicas. Más adelante volveremos sobre él pues regula al respecto todas las condiciones, posibilidades y límites de la investigación cientifica en este ámbito. Por ello, reitero, su contenido es de vital importancia.

49 La Carta de Derechos Fundamentales de la Unión Europea fue aprobada en la Cumbre de Niza de 18 de diciembre del año 2000 . En ella se recogen una serie de derechos ya reconocidos en otras Declaraciones y otro nuevos. Pero la Carta tiene sólo un valor declarativo, no jurídico. Una vez más razones políticas han impelido que pueda ser ratificada como un Convenio de carácter obligatorio. A pesar de todo queda patente la decisión de proteger la dignidad humana con carácter prioritario, pues se entiende que ella, la dignidad, es el fundamento mismo de la Unión Europea.

50 Artículo uno de la Carta de Derechos Fundamentales de la Unión Europea.

51 Artículo cuarto del Nuevo Código de Ética y Deontología Médica, aprobado por la Asamblea general de la Organización Médica Colegial (OMC) el 31 de marzo de 1990. Desde su aprobación, a tenor del artículo final la propia OMC se obliga a revisar este Código cada dos años, $o$ antes, si urgentes planteamientos lo requieren, para adaptarlo y actualizarlo al desarrollo de los principio éticos que han de 
informar en cada momento la conducta profesional. A pesar de las diferentes revisiones y modificaciones, el texto citado permanece inalterado.

52 Entre la numerosa bibliografía existente al respecto cabe destacar un magnífico capítulo de Diego Gracia titulado Libertad de investigación y biotecnologia en Dilemas éticos de la medicina actual, 7: ética y biotecnología, Javier Gafo editor, Publicaciones de la Lniversidad Pontificia de Comillas, Madrid, 1993, pp. 13-29. Y cabe destacar también el trabajo de Ángela APARıSI, Manipulación Genética, Dimnidad y Derechos Humanos en Persona y Derecho (Estudios en homenaje a] Prof. Javier Hervada - II), $\mathrm{N}^{\circ} 41$, Pamplona 1999, pp. 275-318.

53 La libertad de pensamiento se proclama en el artículo 18 de la Declaración Universal de Derechos Humanos, de 10 de diciembre de 1948, como libertad inherente a toda persona. De ella se deriva la libertad de investigación expresada en el artículo 19.

54 Art. 19 de la Declaración Universal de Derechos Humanos.

55 Art. 27.1 de la Declaración Universal de Derechos Humanos.

56 GraCli, Diego, Libertad de investigación y biotecnología en Dilemas éticos de la medicina actual 7: ética y biotecnologia; Javier GAFO, editor, Publicaciones de la Liniv. Pontificia de Comillas, Madrid, 1993, pg.13.

57 Ibidem.

58 Peces-Barba Martínez, G., La libertad del hombre y el genoma, en AA VV, El Derecho ante el Proyecto Genoma Humano, Tomo I, Fundación BBV, Madrid 1994, pg. 202.

59 Véase el artículo 27.1 de la Declaración Universal de Derechos Humanos.

60 Art. 29.2 y 3 de la Declaración Universal de Derechos Humanos.

61 Apartsi, Angela, Manipulación genética, dignidad y Derechos Humanos, cit., pp 294295

62 Recuérdese al efecto que por persona se entiende cualquier individuo de la especie humana En una concepción amplia de la persona, capaz de sostener la universalidad de los Derechos Humanos sin reduccionismos o relativismos que puedan ponerlos en duda, se sostiene que el hombre es persona desde el momento en que comienza a ser humano y mientras permanezca con vida. No se exige de él, por tanto, que acredite la posesión de determinadas características particulares para ser reconocido como un fin en sí: la simple pertenencia a la especie humana le basta para ser tenido por digno del respeto que se debe a las personas. Véase R. AndonNo, Bioética $y$ dignidad de la persona, cit., pag 65.

"En este enfoque el concepto de persona" se aplica a todo ser humano vivo aun cuando no haya desarrollado aún todas sus potencialidades (como en el feto, en el recien nacido o en el niño), o que las haya perdido irremediablemente (como en ciertos casos de demencia especialmente graves)". Ibidem, pg 63.

63 Véase el artículo 20 de la Constitución Española. En el apartado b del $n^{\circ} 1$ se reconoce y protege el derecho a la (investigación) producción científica y técnica. En el mismo artículo se reconocen también otros derechos relacionados con la libertad de pensamiento.

64 Punto 4 del artículo 20 de la Constitución Española.

65 Graci, Diego, Libertad de investigación y biotecnologia, cit., pg. 20.

66 Gruci.A, D., Libertad de investigación y biotecnologia, cit., pg. 20.

67 En el artículo dos se establece el derecho a la vida y la prohibición de la pena de muerte. En el artículo tres los derechos que deben respetarse en el ámbito de la medicina y la 
biología. Todo ello con la prohibición de la tortura y los tratos inhumanos y degradantes del artículo cuatro

68 Artículo 5, apartudo d) de la Declaración Universal sobre el Genoma Humano y los Derechos Humanos.

69 Artículo 6 de la misma Declaración.

70 Baste recordar que ya la Comunidad Internacional obligó a destruir las armas de destrucción masiva (nucleares y bacteriológicas) a Sur África y a Ucrania y recientemente Estados Unidos, aunque sin consenso con la Comunidad Internacional, ha intervenido militarmente en Irak ante la resistencia y negativa de Sadam Husein a destruir su arsenal de armas químicas. En relación con el desplazamiento de la legitimidad del Estado hacia la Comunidad Internacional véase cl texto que da lugar a nota 66 de este mismo trabajo.
71 Así se expresa en los artículos 20 y 21 de la Declaración Universal sobre el Genoma Humano y los Derechos Humanos.

72 Véanse las páginas 204-215 de la obra Bioética: orígenes, presente $y$ futuro de Francesc ABEL I FABRE. Instituto Borja de bioética, Fundación Mapfre Medicina. En las páginas que se citan se exponen las actitudes necesarias para un auténtico diálogo bioético.

73 Artículo 15 del Convenio para la Protección de los Derechos Humanos y la dignidad del ser humano.

74 Dri Barco, J. L., Bioética y dignidad humana en AA. V., Bioética, consideraciones filosóficateológicas sobre un tema actual, Madrid, 1992, pg.11. 